\title{
Respiration Modulates Olfactory Memory Consolidation in Humans
}

\author{
(-Artin Arshamian, ${ }^{1,2,3,4}$ - Behzad Iravani, ${ }^{1}{ }^{-}$Asifa Majid, ${ }^{2,3,5,6 *}$ and ${ }^{\oplus J}$ Johan N. Lundström ${ }^{1,7,8 *}$ \\ ${ }^{1}$ Department of Clinical Neuroscience, Karolinska Institutet, 17177 Stockholm, Sweden, ${ }^{2}$ Donders Institute for Brain, Cognition, and Behavior, 6500 HD \\ Nijmegen, The Netherlands, ${ }^{3}$ Center for Language Studies, Radboud University, 6500 HD Nijmegen, The Netherlands, ${ }^{4}$ Department of Psychology, \\ Stockholm University, 10691 Stockholm, Sweden, ${ }^{5}$ Max Planck Institute for Psycholinguistics, Nijmegen, The Netherlands, ${ }^{6}$ University of York, Heslington, \\ York, Y010 5DD, United Kingdom, ${ }^{7}$ Monell Chemical Senses Center, Philadelphia, Pennsylvania 19104, and ${ }^{8}$ Department of Psychology, University of \\ Pennsylvania, Pennsylvania 19104, Philadelphia
}

In mammals respiratory-locked hippocampal rhythms are implicated in the scaffolding and transfer of information between sensory and memory networks. These oscillations are entrained by nasal respiration and driven by the olfactory bulb. They then travel to the piriform cortex where they propagate further downstream to the hippocampus and modulate neural processes critical for memory formation. In humans, bypassing nasal airflow through mouth-breathing abolishes these rhythms and impacts encoding as well as recognition processes thereby reducing memory performance. It has been hypothesized that similar behavior should be observed for the consolidation process, the stage between encoding and recognition, were memory is reactivated and strengthened. However, direct evidence for such an effect is lacking in human and nonhuman animals. Here we tested this hypothesis by examining the effect of respiration on consolidation of episodic odor memory. In two separate sessions, female and male participants encoded odors followed by a $1 \mathrm{~h}$ awake resting consolidation phase where they either breathed solely through their nose or mouth. Immediately after the consolidation phase, memory for odors was tested. Recognition memory significantly increased during nasal respiration compared with mouth respiration during consolidation. These results provide the first evidence that respiration directly impacts consolidation of episodic events, and lends further support to the notion that core cognitive functions are modulated by the respiratory cycle.

Key words: consolidation; episodic; hippocampus; memory; odor; respiration

\section{Significance Statement}

Memories pass through three main stages in their development: encoding, consolidation, and retrieval. Growing evidence from animal and human studies suggests that respiration plays an important role in the behavioral and neural mechanisms associated with encoding and recognition. Specifically nasal, but not mouth, respiration entrains neural oscillations that enhance encoding and recognition processes. We demonstrate that respiration also affects the consolidation stage. Breathing through the nose compared with the mouth during consolidation enhances recognition memory. This demonstrates, first, that nasal respiration is important during the critical period were memories are reactivated and strengthened. Second, it suggests that the neural mechanisms responsible may emerge from nasal respiration.

\section{Introduction}

Even when there is no odor, mammalian olfactory sensory neurons detect the mechanical pressure caused by airflow in the nos-

Received Nov. 27, 2017; revised Aug. 14, 2018; accepted Aug. 30, 2018.

Author contributions: A.A. wrote the first draft of the paper; B.I. edited the paper. A.A., A.M., and J.N.L. designed research; A.A. performed research; A.A., B.I., and J.N.L. analyzed data; A.A., A.M., and J.N.L. wrote the paper.

This work was funded by an international postdoctoral Grant from the Swedish Research Council VR 2014-00240 (A.A.), The Netherlands Organization for Scientific Research: NWO VICI Grant “Human olfaction at the intersection of language, culture and biology" 277-70-011 and Ammodo KNAW Award (A.M), and the Knut and Alice Wallenberg Foundation KAW 2012.0141 (J.N.L). We thank Martin Schaefer for assistance with data collection.

The authors declare no competing financial interests.

*A.M. and J.N.L. contributed equally to this work. tril (Grosmaitre et al., 2007). This information reaches the olfactory bulb (Freeman, 1976; Fontanini et al., 2003; Courtiol et al., 2011; Rojas-Líbano et al., 2014), which generates oscillations that reach the piriform cortex where they propagate further downstream to the hippocampal formation, and beyond to somatosensory cortex and prefrontal networks (Adrian, 1942; Kay and Freeman, 1998; Fontanini et al., 2003; Fontanini and Bower, 2005, 2006; Kay et al., 2009; Ito et al., 2014; Kay, 2014; Yanovsky

Correspondence should be addressed to Dr. Artin Arshamian, Department of Clinical Neuroscience, Karolinska Institutet, 17177 Stockholm, Sweden. E-mail: artin.arshamian@ki.se.

https://doi.org/10.1523/JNEUROSCI.3360-17.2018

Copyright $\odot 2018$ the authors $\quad 0270-6474 / 18 / 3810286-09 \$ 15.00 / 0$ 


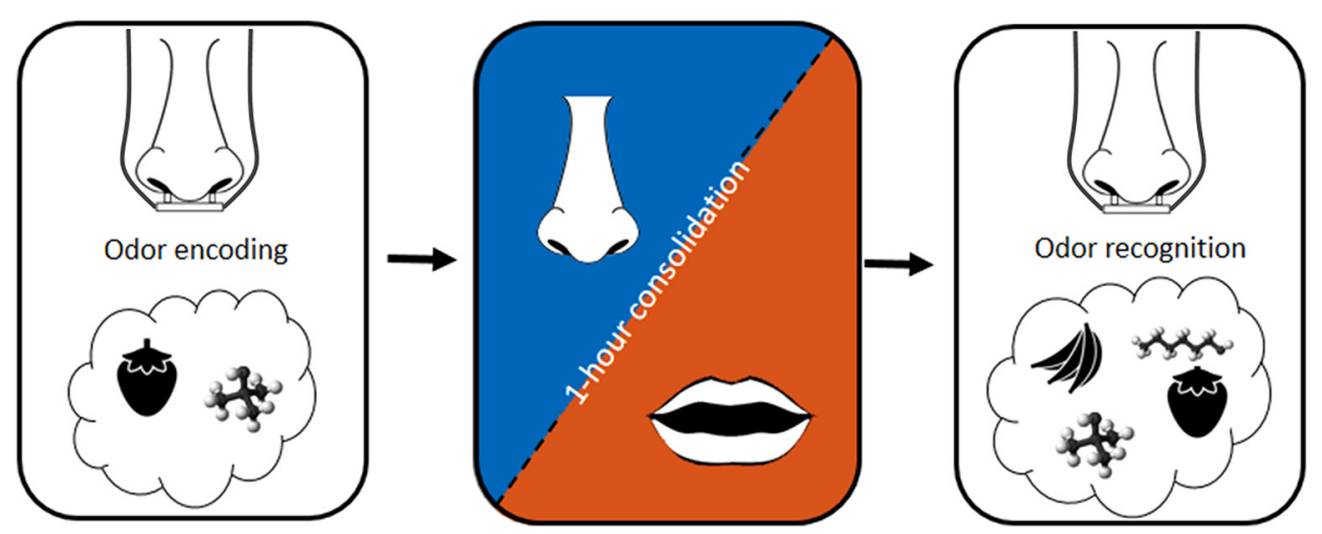

Figure 1. Schematic of experimental paradigm. The experiment consisted of two separate sessions, each including an encoding, a consolidation, and a recognition phase. In the encoding phase, participants were presented with six familiar (e.g., strawberry) and six unfamiliar (e.g., 1-butanol) odors one at a time and asked to remember them. The odors familiarity was predefined and a new set of odors were used in each session. After the encoding phase, participants rested passively without sleeping (consolidation phase) for $1 \mathrm{~h}$ during which they either breathed through their nose (nasal consolidation) or mouth (mouth consolidation). Next, during the odor recognition phase, participants were once again presented with the odors from the encoding phase but this time intermixed with 12 new odors ( 6 familiar and 6 unfamiliar odors). For each odor, participants made a recognition judgment if the odor was new or old. Next participants rated odor intensity, pleasantness, familiarity, and nameability, as well as trying to identify the odor. During both encoding and recognition, nasal airflow was monitored by a nasal cannula, which enabled measurement of sniff parameters during odor presentation.

et al., 2014; Nguyen Chi et al., 2016; Biskamp et al., 2017; Heck et al., 2017; Zhong et al., 2017). These oscillations have been implicated in the scaffolding and transfer of information between sensory and memory networks, and shown to modulate learning and perception in rodents (Fontanini et al., 2003; Fontanini and Bower, 2005, 2006; Kay et al., 2009; Ito et al., 2014; Kay, 2014, 2015; Yanovsky et al., 2014; Biskamp et al., 2017; Heck et al., 2017; Zhong et al., 2017; Tort et al., 2018).

Removing or inhibiting the olfactory bulb, or bypassing nasal airflow through tracheotomy or mouth-breathing, abolishes these activations in animals (Ito et al., 2014; Yanovsky et al., 2014; Liu et al., 2017; Zhong et al., 2017). In humans too, nasal respiration entrains hippocampal oscillatory activity (Zelano et al., 2016), and recognition memory is enhanced at peak inhalation during nasal, but not mouth, respiration both at the encoding and recognition phases of memory formation (Zelano et al., 2016). However, the specific pathway for this is not clear because it is still unknown whether respiratory oscillations propagate from piriform cortex to hippocampus in humans.

Whether nasal respiration modulates the consolidation phase, the off-line stage between encoding and recognition, where memory is reactivated and strengthened is not known. Recently it has been demonstrated that the nasal respiratory cycle entrains hippocampal sharp-wave ripples (SWRs) in awake mice (Liu et al., 2017). It has been suggested that respiration-locked hippocampal oscillations modulate the probability of SWRs, and that reducing these should subsequently reduce SWRs (Liu et al., 2017). Hippocampal oscillations and SWRs are both essential for memory consolidation (Buzsaki, 2006; Axmacher et al., 2008; Girardeau et al., 2009; Carr et al., 2011; Jadhav et al., 2012; Buzsáki, 2015). So it has been hypothesized that for hippocampaldependent memory, akin to encoding and recognition, nasal respiration should modulate consolidation processes (Fontanini and Bower, 2006; Liu et al., 2017).

We test this hypothesis directly by examining the effect of respiration on consolidation of episodic memory in humans. We studied this effect in awake consolidation because SWRs are most frequent when the participant is immobile and resting, but not asleep (Axmacher et al., 2008). In two separate sessions, participants encoded odors followed by a $1 \mathrm{~h}$ awake resting consolidation phase where they either breathed solely through their nose or mouth. We predicted that nasal compared with mouth respiration during consolidation would enhance episodic memory. To ensure our breathing manipulation specifically targeted memory consolidation, we also conducted a control experiment measuring the effect of breathing on attention. It could be hypothesized that our experimental manipulation (nose- vs mouth-breathing) differentially affected attentional control; for example, people who are habitual nose-breathers could have had to pay more attention to their breathing in the mouth-breathing condition, thereby influencing their memory indirectly. We rule out this possibility in a control experiment below.

\section{Materials and Methods}

Participants. Twenty-four healthy participants between 19 and 25 years $(\mathrm{M}=22.2, \mathrm{SD}=1.8 ; 12$ women $)$ participated in the main experiment (consolidation study). Participants were recruited via the internal recruiting system within Radboud University Njimegen, and provided written informed consent before enrollment in the study. The study was approved by the local ethics committee at Radboud University. In the control experiment assessing respiratory effects on sustained and selective attention, a different 24 healthy participants between 19 and 49 years $(\mathrm{M}=27.3, \mathrm{SD}=6.0 ; 13$ women $)$ participated. These participants were recruited via the internal recruiting system available within Karolinska Institute, Stockholm, and provided written informed consent before enrollment in the study. The control experiment was approved by the Stockholm County local research ethics committee.

Procedure main experiment. The consolidation experiment consisted of two separate sessions $2 \mathrm{~d}$ apart. Each session was divided into three phases: encoding, consolidation, and recognition (Fig. 1). In one session participants breathed through their nose (nasal consolidation: tape over mouth); in another session participants breathed through their mouth (mouth consolidation: nasal clip) during a $1 \mathrm{~h}$ consolidation phase (i.e., while passive resting).

In the first phase, during encoding, participants were connected to a nasal cannula and presented with a set of 12 odors one-by-one that they were instructed to memorize. Immediately after the encoding phase, participants were assigned to one of the two breathing conditions. They were disconnected from the nasal cannula and relocated to a resting room where they were seated in an armchair facing a white wall. Participants were not allowed to stand-up, sleep, talk, read, or remove the nasal clip/mouth tape during the $1 \mathrm{~h}$ resting consolidation phase. Compliance was controlled by an experimenter seated in the resting-room with the participant under the pretense that they would monitor the participants' 
oxygen level. After consolidation participants relocated to the testing room and rated the unpleasantness of the blocking procedure. They were then reconnected to the nasal cannula and instructed that they would be presented with odors one-by-one and their task was to judge whether the odors were present in the encoding phase or not (i.e., an old or new odor). Recognition memory for the encoded odors was tested by presenting the 12 target odors mixed with 12 new lures. After each recognition judgment they had to rate the odors pleasantness, intensity, familiarity, and nameability, as well as try to produce a label for the odor. Odor ratings were measured on 7-point Likert scales. Odor pleasantness: 1 (unpleasant)-7(pleasant); Odor intensity: 1(weak)-7(strong); Odor familiarity: 1(unfamiliar)-7(familiar); Odor nameability: 1(unameable)7 (nameable). As odor familiarity and odor identification affect odor memory predefined high and low familiar odors were used both in the encoding and recognition phases (Larsson, 1997; Zelano et al., 2009; Saive et al., 2014; Cornell Kärnekull et al., 2015).

Odor presentation and sniffing. Nasal respiration was monitored by the experimenter continuously throughout the encoding and recognition phases. Odors were presented to both nostrils for $\sim 3 \mathrm{~s}$, with a jittered interstimulus interval between 20 and $30 \mathrm{~s}$. Odors were presented at the nadir of the participants' nasal exhalation. Participants were blindfolded during both the encoding and recognition phases and were instructed to inhale when presented with an odor. After the first encoding phase, participants were randomized to start with either the nose- or mouthblocking session.

Breathing technique. During the consolidation phase participants breathed either through their nose or mouth using standard techniques to block nose (nasal clips) or mouth (tape straps) (Verrall et al., 1989; Prem et al., 2013; Turkalj et al., 2016). Before the start of the first session participants matched the physical pressure of the nasal clip and the tape by manually adjusting them until they had the same perceived pressure. This was done to keep any discomfort resulting from the breathing techniques as similar as possible between the two sessions.

Cover story. Participants were told that the aim of the experiment was to observe the effect of blood oxygen level on memory, which was modulated by breathing format (through nose or mouth). This was implemented to minimize demand characteristics. Participants were informed that their blood oxygen level would be measured by a finger-pulse oximeter that they would wear during the whole experiment, as well as by a nasal cannula during encoding and testing for increased precision. The word sniffing was never mentioned during the experiment. At the end of the two sessions, participants were asked what they thought the purpose of the experiment was. All but one stated that the aim was how oxygen level affected odor memory.

The remaining participant believed that the aim was to study the effect of enclosing odors in the nose on odor memory, with the notion that a nasal clip would help the odor information flow to the brain, and subsequently enhance performance. They were also asked if they could generate an alternative aim of the study. Of the participants that could, no-one guessed the true aim of the study, nor mentioned sniffing or type of breathing.

Randomization. Odors were pseudo-randomized to ensure equal amount of predefined familiar and unfamiliar odors across sessions. They were divided into four odors sets, with each set having 12 low familiar ( 6 at encoding and 12 at recognition) odors and 12 high familiar ( 6 at encoding and 12 at recognition). Familiarity ratings of the odors did not differ between the predefined familiar and unfamiliar odors across sessions (familiar odors: $t_{(23)}=0.65, p=0.53$; unfamiliar: $t_{(23)}=0.55$, $p=0.59$, paired $t$ tests). Bayesian paired samples $t$ tests showed that all Bayes factors $\left(\mathrm{BF}_{01}\right)$ were in favor of the null hypothesis that odor familiarity did not differ between sessions (familiar: $\mathrm{BF}_{01}=3.857$, error $=$ 0.04; unfamiliar odors: $\mathrm{BF}_{01}=4.063$, error $=0.04$ ). The presentation of the four sets of odors was pseudo-randomized across conditions and participants. The presentation order for the odors within a set was randomized across participants. To ensure that the order of sessions was counterbalanced across participants, order was pseudorandomized with half the participants starting with nasal, and the other half with mouth consolidation. Furthermore, both the participant and the experimenter were blind to the session order until the compilation of the first encoding phase.

Materials. Respiratory parameters were continuously recorded during encoding and recognition at $1000 \mathrm{~Hz}$ birhinally with a nasal cannula coupled with a pneumotachograph that relayed changes in intranasal pressure to an amplifier PowerLab 4/35 recording system (AD Instruments). The transduced signals were extracted and down sampled to 100 $\mathrm{Hz}$ with LabChart 7. Oxygen level was measured with a Contec Pulse Oximeter CMS50D. In the main experiment, monomolecular and odor mixtures from Sigma-Aldrich, Burghart Messtechnik, and International Flavors and Fragrances were presented using Sniffin' Sticks (Hummel et al., 1997).

Attentional control experiment. In the control experiment, sustained attention was measured using the Sustained Attention to Response Task (SART; Robertson et al., 1997), and selective attention was measured using a color-word Stroop task (Stroop, 1935). The SART task measures the ability to respond to repetitive, non-arousing stimuli. It is a Go/NoGo task where the NoGo stimulus is presented very infrequently, thus increasing habituation and distraction. Participants were presented with streams of single digits (1-9) in a randomized order and responded with a key press if any digit other than 3 was displayed, and told to withhold the response if 3 was presented. In the Stroop task, participants have to name the ink color of congruent or incongruent color words. Incongruent words normally result in slower response time, a finding attributed to selective allocation of attention to eligible responses (Lamers et al., 2010). Before the start of the experiment, participant's ran one test block on each attentional task to minimize test-retest effects. As with the consolidation experiment, participants had to rest with either their nose or mouth blocked (same procedure as in consolidation experiment). After 10 min rest they conducted the two attentional tasks with either their nose or mouth still blocked. After this, they switched blocking procedure and again rested for $10 \mathrm{~min}$ before repeating the attentional tasks with either nose or mouth blocked. All blocking procedures and attentional tasks were pseudorandomized across participants. Both SART and the color-word Stroop task were presented using Inquisit Lab v4 (Millisecond Software).

Statistical analysis. We used signal detection theory (SDT) for recognition memory using d-prime $\left(d^{\prime}\right)$ as the measure of sensitivity defined as the difference between $z$-transformed hit $(\mathrm{H})$ and false alarm rate (FA); $d^{\prime}=z(\mathrm{H})-z(\mathrm{FA})$ (Macmillan and Creelman, 2005). Thus, $d^{\prime}$ is an unbiased measure of recognition memory. Hit and false alarm rates of 1 and 0 were adjusted to $1-1 /(2 N)$ and $1 /(2 N)$, respectively, where $N$ is the number of trials (Macmillan and Creelman, 2005). To determine significant main effects and interactions, data were analyzed using repeated-measures ANOVA with partial $\eta$ square $\left(\eta_{p}^{2}\right)$ as the effect size. Odor ratings were analyzed using two-tailed paired samples Student's $t$ tests. Alpha was set at 0.05 .

Parallel to these tests, we also assessed the main results using a Bayesian approach because it, contrary to classical null hypothesis significance testing (NHST): (1) can quantify evidence in favor of $\mathrm{H}_{0}$, (2) enables comparison between different models (e.g., $\mathrm{H}_{0}$ vs $\mathrm{H}_{1}$ across main effects and interactions), and (3) is not biased against $\mathrm{H}_{0}$, unlike NHST (Rouder et al., 2012, 2017; Wagenmakers et al., 2018). We used a Bayesian repeated-measures ANOVA which is an equivalent to a repeatedmeasures ANOVA (Rouder et al., 2012, 2017), using $d^{\prime}$ as the dependent variable. Respiration type (nasal, mouth) was entered as a withinparticipants factor (default prior of: $r$ scale fixed effects $=0.5 ; r$ scale random effects $=1$ ). Paired-sample Bayesian $t$ tests, an equivalent to paired-sample $t$ tests were further used to analyze odor ratings and used a default Cauchy prior $=0.707$ (Jeffreys, 1961; Rouder et al., 2009; Morey et al., 2011).

For both the Bayesian ANOVA and the $t$ tests, we used the default priors (as implemented in JASP) because they place mass in realistic ranges without being overcommitted to any one point. Also, they have been shown to fit a large set of psychological data with moderate effect sizes, and convey a minimum degree of information without being uninformative (Rouder et al., 2009, 2012, 2017). The BF depicts an odds ratio, the probability of the data under one hypothesis relative to another 


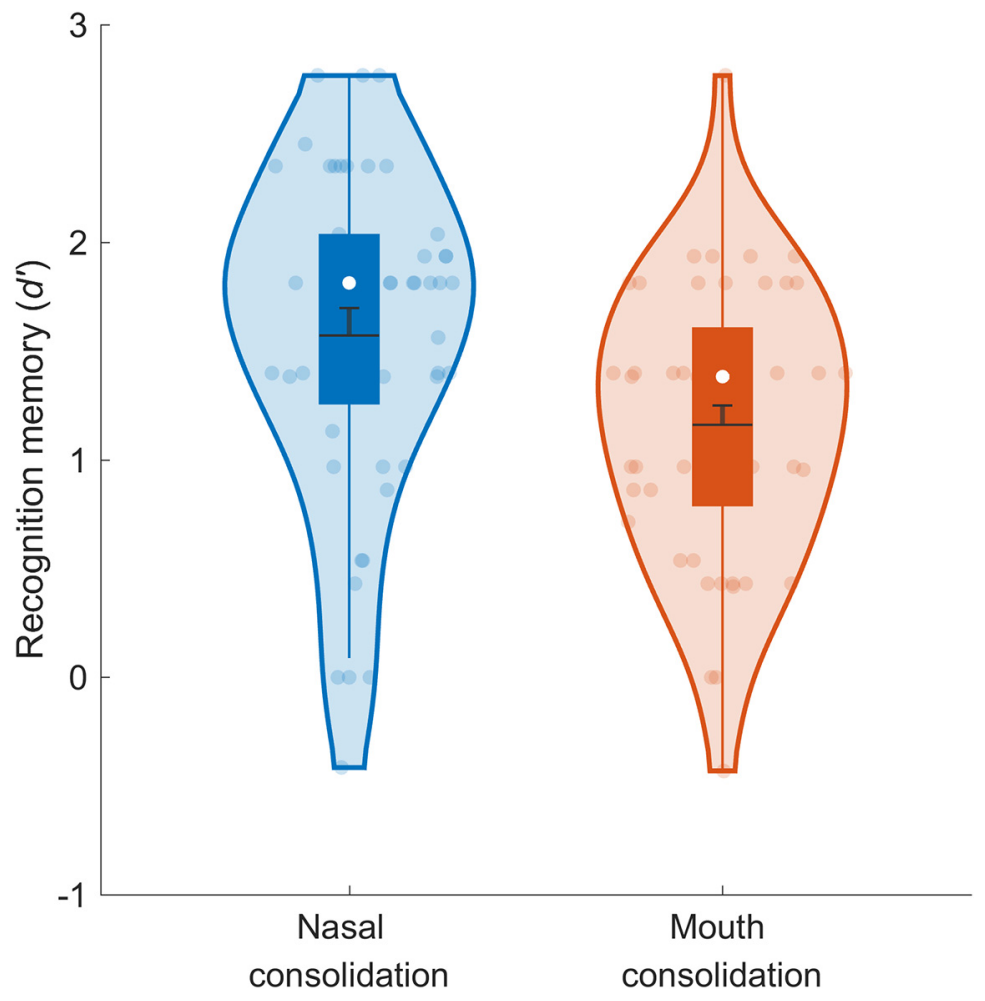

Figure 2. Recognition memory $\left(d^{\prime}\right)$ as function of nasal and mouth respiration during consolidation. Violin plot for recognition memory using the sensitivity index $d^{\prime}$ after nasal and mouth consolidation sessions. The $d^{\prime}$ was calculated for the familiar and unfamiliar odors separately but for simplicity are collapsed here. The boxes indicate the 75 th (upper horizontal line), mean + SEM (black bold horizontal line), median (white dot), and the 25th (lower horizontal line), percentiles of the distribution. The upper whiskers indicate the maximum value of the variable located within a distance of 1.5 times the interquartile range above the 75 th percentile. The lower whiskers indicate the corresponding distance to the 25 th percentile value. Surrounding the boxes (shaded area) on each side is a rotated kernel density plot, which is comparable to a histogram with infinitely small bin sizes.

memory, with higher $d^{\prime}$ indicating greater odor recognition. As odor familiarity plays an important role in odor memory, $d^{\prime}$ was calculated according to our predefined high and low familiarity targets and lures. This enabled a separate sensitivity measure $\left(d^{\prime}\right)$ for familiar and unfamiliar odors that was then submitted to a 2 (respiration modality: nasal, mouth) $\times 2$ (odor familiarity: high, low) repeatedmeasures ANOVA. This demonstrated a main effect of consolidation $\left(F_{(1,23)}=\right.$ 12.50, $\left.p=0.002, \eta_{p}^{2}=0.35\right)$. Breathing through the nose for $1 \mathrm{~h}$ during memory consolidation increased recognition memory compared with $1 \mathrm{~h}$ of mouth-breathing, regardless of familiarity (nasal consolidation: familiar $\mathrm{M}=1.63, \mathrm{SD}=0.73$, unfamiliar $\mathrm{M}=1.52, \mathrm{SD}=0.81$; mouth consolidation: familiar $\mathrm{M}=1.27, \mathrm{SD}=$ 0.71 , unfamiliar $\mathrm{M}=1.05, \mathrm{SD}=0.53$; Fig. 2). There was no main effect of familiarity $\left(F_{(1,23)}=1.34, p=0.26, \eta_{p}^{2}=0.06\right)$, and no interaction between respiration during consolidation and familiarity $\left(F_{(1,23)}=0.18\right.$, $p=00.67, \eta_{p}^{2}=0.01$ ).

When the control ratings (intensity, pleasantness, familiarity, nameability, and discomfort) between sessions were entreated as covariates in the repeatedmeasures ANOVA, there was no change to the overall pattern of results, and they are therefore excluded in the analysis reported below. Moreover, there were no statistical differences in ratings across

Table 1. Bayesian model comparison: $d^{\prime}$ as a function of respiration modality and odor familiarity

\begin{tabular}{llllrl}
\hline Models compared to the null model & $\mathrm{P}(\mathrm{M})$ & $\mathrm{P}\left(\mathrm{M}_{1}^{\prime}\right.$ data $)$ & $\mathrm{BF}_{\mathrm{M}}$ & $\mathrm{BF}_{10}$ & Error, \% \\
\hline Null model (including subject) & 0.200 & 0.028 & 0.115 & 1.000 & \\
Respiration modality & 0.200 & 0.605 & 6.139 & 21.741 & 1.439 \\
Odor familiarity & 0.200 & 0.012 & 0.047 & 0.415 & 1.200 \\
Respiration modality + Odor familiarity & 0.200 & 0.273 & 1.505 & 9.814 & 1.826 \\
Respiration modality + Odor familiarity + & 0.200 & 0.082 & 0.356 & 2.936 & 2.109 \\
$\quad$ Respiration modality $\times$ Odor familiarity & & & & &
\end{tabular}

All models include subject. $\mathrm{P}(\mathrm{M})$, Prior model probabilities; $\mathrm{P}\left(\mathrm{M}_{1}^{\prime}\right.$ data), posterior model probabilities; $\mathrm{BF}_{\mathrm{M}}$, change from prior to posterior model odds.

hypothesis. This allows for a clearer interpretation. For instance, $\mathrm{BF}_{10}=$ 4 indicates the data are four times more likely under $\mathrm{H}_{1}$ than under $\mathrm{H}_{0}$. Whereas, a $\mathrm{BF}_{01}=3$ would support $\mathrm{H}_{0}$ three times more than $\mathrm{H}_{1}$. Our interpretation of the BF follow the standard recommendations (Jeffreys, 1961; Jarosz and Wiley, 2014). These state a BF between 1 and 3 imply anecdotal evidence, $3-10$ substantial, and $10-30$ strong evidence. $\mathrm{BF}_{10}$ quantifies evidence for the alternative hypothesis relative to the null hypothesis, whereas $\mathrm{BF}_{01}$ quantifies evidence for the null hypothesis relative to the alternative hypothesis. Statistical analyses were conducted in MATLAB 2015b, MathWorks and the JASP (2018) software package v0.8.6.0 (Love et al., 2018).

\section{Results}

Type of respiration during consolidation modulates episodic odor memory

To quantify the effect of respiration type on episodic odor memory, we used $d^{\prime}$ that serves as an unbiased index of recognition sessions, even without correcting for multiple comparisons (intensity: $t_{(23)}=1.39, p=0.178$; pleasantness $t_{(23)}=-0.09$, $p=0.93$; familiarity: $t_{(23)}=0.75, p=0.50$; nameability: $t_{(23)}=$ $0.88, p=0.39$; discomfort: $\left.t_{(23)}=-1.89, p=0.070\right)$. Importantly, corresponding Bayesian paired samples $t$ tests on the same ratings demonstrated substantial support for the null hypothesis $\left(\mathrm{BF}_{01}\right)$, i.e., there was no difference between sessions for pleasantness $\left(\mathrm{BF}_{01}=4.6\right.$, error $\left.\%=1.16 \mathrm{e}-4\right)$, familiarity $\left(\mathrm{BF}_{01}=3.6\right.$, error $\left.\%=0.04\right)$ and nameability $\left(\mathrm{BF}_{01}\right.$ $=3.3$, error $\%=0.04)$, and only mere anecdotal evidence for the null for intensity $\left(\mathrm{BF}_{01}=2.0\right.$, error $\left.\%=1.03 \mathrm{e}-4\right)$, and discomfort $\left(\mathrm{BF}_{01}=1.0\right.$, error $\left.\%=1.03 \mathrm{e}-4\right)$. Also, there was no statistical difference in how often participants were able to label/verbalize the odors across sessions $\left(t_{(23)}=-1.23, p=\right.$ $0.23 ; \mathrm{BF}_{01}=2.4$, error $\left.\%=1.19 \mathrm{e}-4\right)$.

There is evidence that women have better episodic odor recognition memory then men (Majid et al., 2017); however, we did not have a specific a priori hypothesis about how this might interact with respiration. Specifically testing for an effect of sex by including it in the repeated-measures ANOVA as a betweensubjects factor revealed no additional effects (interaction between sex and respiration: $F_{(1,22)}=0.04, p=0.85, \eta_{p}^{2}=0.00$; between sex, respiration and odor familiarity: $F_{(1,22)}=0.76, p=$ $\left.0.39, \eta_{p}^{2}=0.03\right)$. So this factor was not included in subsequent analyses.

To further estimate the strength of evidence for our data we submitted the $d^{\prime}$ to a Bayesian equivalent of a repeated- 
A
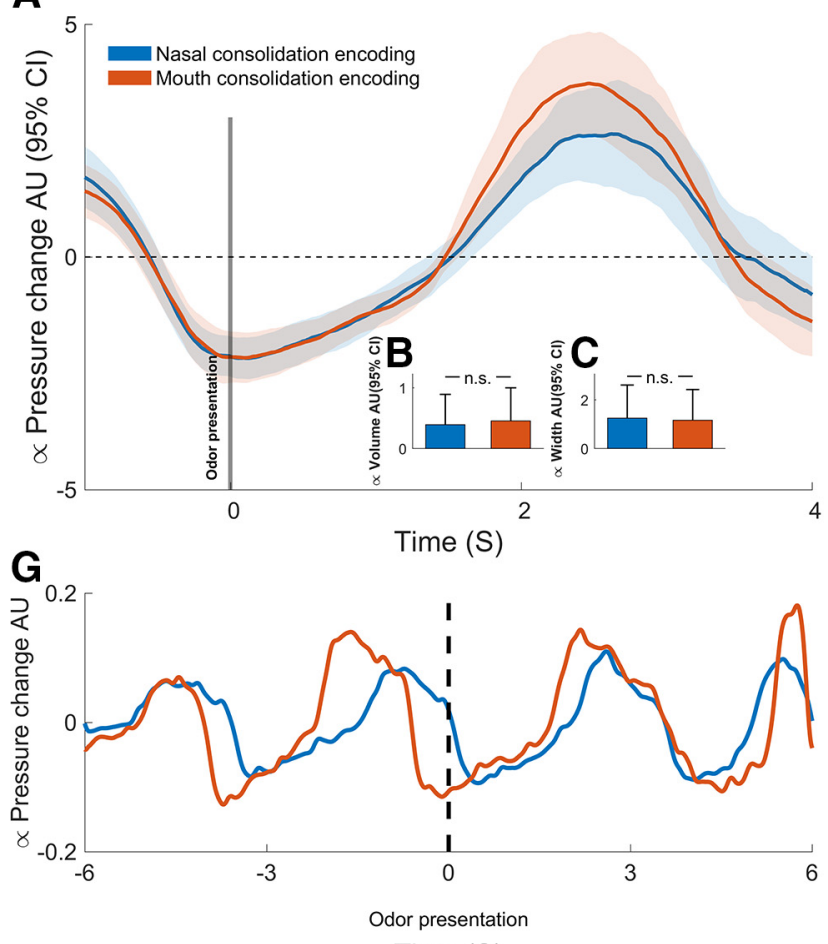

D

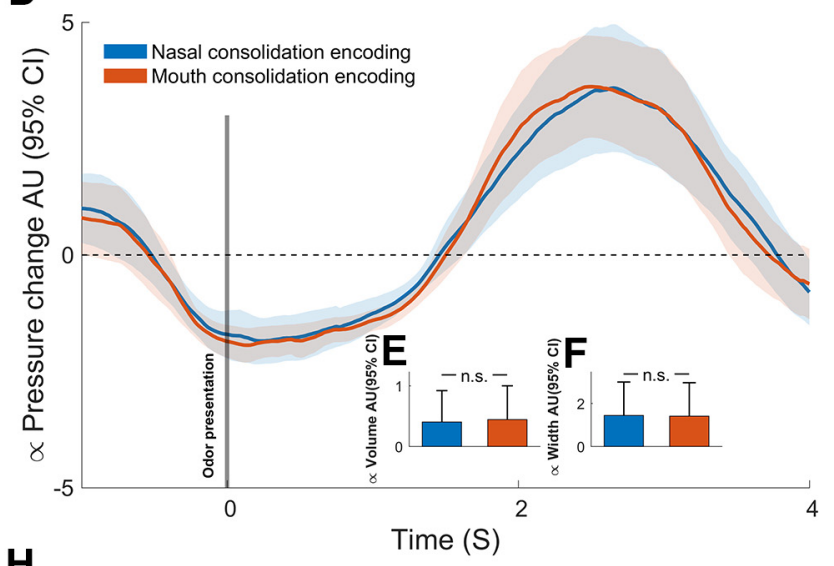

$\mathbf{H}$

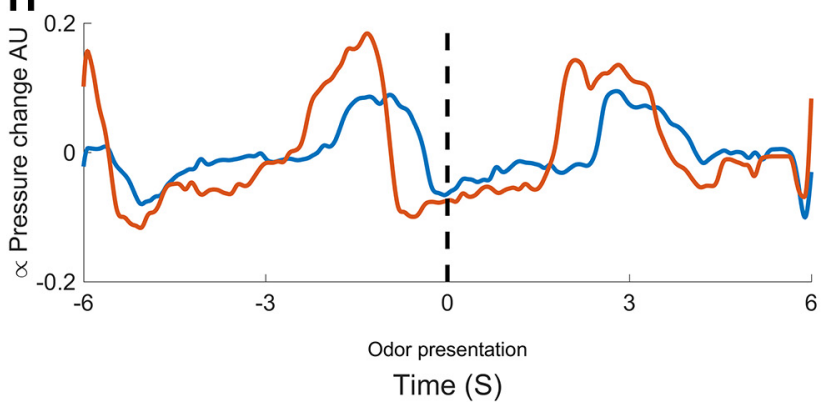

Figure 3. Sniff parameters during odor encoding and recognition across sessions. A, Average continuous sniff response during odor encoding across sessions with $95 \%$ confidence interval (Cl). Gray volume of the $95 \% \mathrm{Cl}$ indicates the area were the nasal consolidation (light blue) and mouth consolidation (light orange) sniffing parameters overlap. B, C, AUC and the FWHM with corresponding $95 \%$ Cl during odor encoding across sessions. $\boldsymbol{D}$, Average continuous sniff response during odor recognition sessions with $95 \%$ Cl. $E, F$, The AUC and the FWHM with corresponding $95 \%$ Cl during odor recognition across sessions. $\mathbf{G}, \boldsymbol{H}$, Data from one participant displaying $12 \mathrm{~s}$ of a 10 -samples moving average continuous respiration ( $6 \mathrm{~s}$ before odor presentation and $6 \mathrm{~s}$ after) during both encoding and recognition for nose and mouth respiration. The unit used is in proportion $(\propto)$ pressure change, measured in arbitrary units (AU).

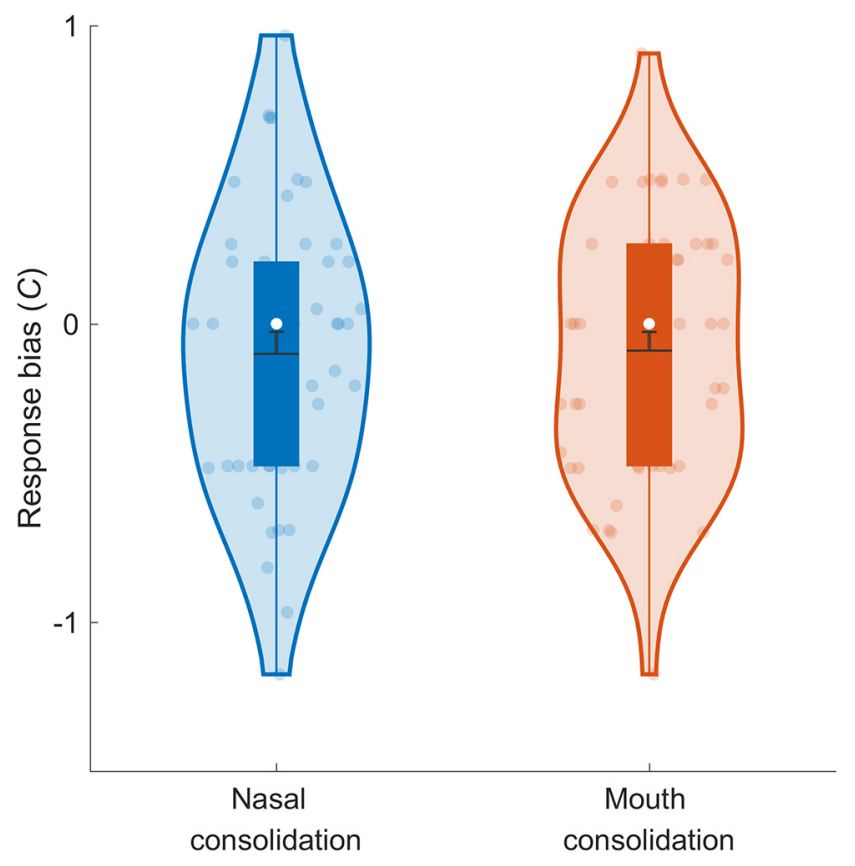

Figure 4. Response bias (c) as function of nasal and mouth respiration during consolidation. Violin plots for response bias c for nasal and mouth consolidation conditions. The c was calculated for the familiar and unfamiliar odors separately but here are collapsed for clarity. For a fuller description of figure markings, see Figure 2. measures ANOVA. Here we compared Bayes factors $\left(\mathrm{BF}_{10}\right)$ for each effect relative to a null modal (i.e., no effect). Compared with the null model, the model that included the main effect of respiration modality during consolidation had a $\mathrm{BF}_{10}$ of 21.74 , thus predicting the data $>21$ times better than the null model (Table 1). This $\mathrm{BF}_{10}$ should be considered as strong evidence in favor of this model. Next, we compared the remaining main effect and interactions models to the null model. These included the main effect of odor familiarity on $d^{\prime}$, the two main effects together (respiration modality and odor familiarity), as well as the interaction. Neither of these models explained the data better than the model with the main effect of respiration modality only.

\section{Both hit and false alarm rate changed as a function of respiration type during consolidation}

To further investigate differences in recognition memory we compared hit and false alarm rates across sessions. Similar to $d^{\prime}$, hit and false alarms rates were submitted to a 2 (respiration modality: nasal, mouth) $\times 2$ (odor familiarity: high, low) repeatedmeasures ANOVA. For hits, this reveled a main effect of respiration modality during consolidation $\left(F_{(1,23)}=6.46, p=\right.$ $\left.0.018, \eta_{p}^{2}=0.22\right)$ a main effect for familiarity $\left(F_{(1,23)}=4.6, p=\right.$ $\left.0.043, \eta_{p}^{2}=0.17\right)$ but no interaction between respiration and familiarity on hit rates $\left(F_{(1,23)}=0.44, p=0.51, \eta_{p}^{2}=0.02\right)$. Likewise, for false alarm rates, there was a main effect of respiration modality during consolidation $\left(F_{(1,23)}=5.85, p=0.024\right.$, $\left.\eta_{p}^{2}=0.20\right)$ but no main effect for familiarity $\left(F_{(1,23)}=0.35, p=\right.$ $\left.0.56, \eta_{p}^{2}=0.02\right)$ nor an interaction between respiration during consolidation and familiarity $\left(F_{(1,23)}=0.01, p=0.93, \eta_{p}^{2}=0.00\right)$. 
A

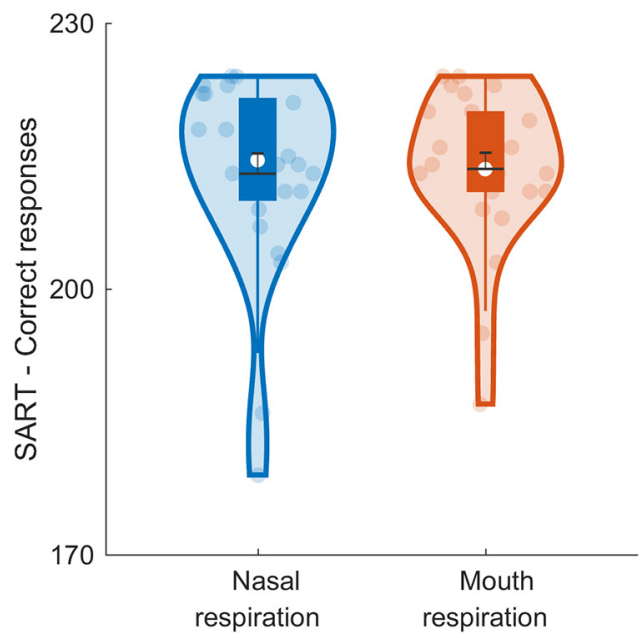

B

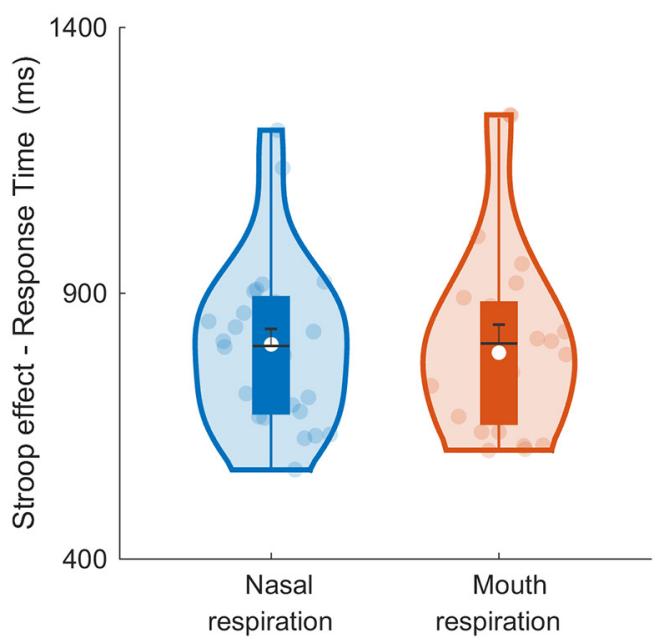

Figure 5. Attentional control as function of respiration route. $\boldsymbol{A}, \boldsymbol{B}$, Violin plots for the SART and the color-word Stroop task measuring selective attention. For description of figure markings, see Figure 2.

We conclude that differences in $d^{\prime}$ between consolidation sessions were driven by differences in both hit and false alarms rates.

\section{Sniffing during odor encoding and recognition did not differ between sessions}

Next, we examined sniffing parameters during odor encoding and recognition and established that they were kept constant between sessions. It is well known that sniffing, the brief and active sampling of odors through the nasal cavity, is essential for odor perception, and the sniff response during odor learning and discrimination are causally linked to hippocampus activity and later performance (Mainland and Sobel, 2006; Kay, 2014). We extracted the continuous sniff response across sessions during encoding and recognition starting from odor presentation onset to $4 \mathrm{~s}$ after. To fully capture various potential differences in sniff parameters we compared the continuous sniff, the area under the curve (AUC), as well as the full width at half maximum (FWHM). There were no statistical differences between sessions in these parameters (see Fig. 3). The difference in $d^{\prime}$ between the two sessions are therefore unlikely to be explained by differences in sniff parameters during odor encoding and recognition.

\section{Respiration type during consolidation does not affect response bias}

Experimental manipulations in recognition memory can often induce changes in response bias, for example, by inducing distraction, or changing attention and motivation. These effects can come from both external and internal sources including differences in environment, participants' estimated degree of learning during conditions, perceived difficulty of the lures or the task itself, as well as from item characteristics such as familiarity (Benjamin et al., 2009). Therefore, we examined and compared the decision-making strategies across the two consolidation sessions. According to a SDT perspective, participants evaluate targets and distractors on a scale of strength. The decision criterion $(c)$ indicates the degree of strength that has to be exceeded for an item to be accepted as previously experienced. The response bias $c$ is a SD unit measuring the level of preference for answering "old" (smelled the odor previously) or "new" (not smelled the odor previously). Negative values indicate a liberal response bias with a tendency to respond old, positive values indicate a conservative response bias with a tendency to respond new, and zero indicates a neutral, unbiased response (Macmillan and Creelman, 2005).

To directly compare whether the decision-making strategies across the two consolidation sessions differed, as before, we submitted $c$ to a 2 (respiration format: nasal, mouth) $\times 2$ (odor familiarity: high, low) repeated-measures ANOVA. This demonstrated that the response bias $(c)$ was not affected by respiration modality during consolidation (nasal consolidation: familiar $\mathrm{M}=-0.157, \mathrm{SD}=0.416$, unfamiliar $\mathrm{M}=-0.044, \mathrm{SD}=0.50$; mouth consolidation: familiar $\mathrm{M}=-0.183, \mathrm{SD}=0.39$, unfamiliar $\mathrm{M}=0.004, \mathrm{SD}=0.46$. There was no main effect for respiration modality during consolidation $\left(F_{(1,23)}=0.04, p=0.85, \eta_{p}^{2}=\right.$ $0.00)$ and no main effect for familiarity $\left(F_{(1,23)}=2.46, p=0.13\right.$, $\left.\eta_{p}^{2}=0.10\right)$ nor an interaction $\left(F_{(1,23)}=0.23, p=0.64, \eta_{p}^{2}=0.01\right.$; Fig. 4).

\section{Respiration type does not affect attentional control}

Differences in recognition memory between the two consolidation sessions could potentially be biased by differences in attentional control during the two breathing modes. To rule out this possibility, we conducted a second experiment with a new set of 24 participants (see Materials and Methods) to measure whether breathing affected attentional control. Specifically, we tested participants sustained-attention as well as a selective-attention as a function of respiration modality.

Sustained attention, as measured by correct responses in SART, did not significantly differ between nasal and mouth respiration $\left(t_{(23)}=-0.68, p=0.51\right)$, nor did selective attention as measured by reaction time for correct responses for incongruent color-words in the Stroop task $\left(t_{(23)}=-0.24, p=0.81\right.$; Fig. 5). Along the same lines, Bayesian paired $t$ test substantially supported the null hypothesis that attentional control was not affected by breathing procedure (sustained-attention: $\mathrm{BF}_{01}=3.8$, error $\%=0.03$; selective-attention: $\mathrm{BF}_{01}=4.5$, error $\%=0.04$ ).

\section{Discussion}

We demonstrated that breathing through the nose, as compared with the mouth, during awake memory consolidation enhances the ability to recognize episodic events. We used both high and low familiar odors because, although both are hippocampal dependent, they draw on partially different types of memory pro- 
cesses. High familiar odors engage more semantic networks, compared with more perceptual engagement for low familiar odors (Larsson, 1997; Zelano et al., 2009; Saive et al., 2014; Cornell Kärnekull et al., 2015). The fact that respiration-type modulates consolidation independent of odor familiarity indicates this effect may not be limited to episodic events involving odors per se, but could generalize to hippocampal-dependent consolidation of items across modalities. The latter remains to be tested, however.

In contrast, respiration-type did not differentially influence external or internal factors that potentially affect distraction, attention, and motivation, as changes in these parameters would have been reflected in participants' response bias across sessions. Additional evidence for this comes from the attentional control experiment where respiration modality did not differentially impact sustained- or selective-attention. A skeptic could nevertheless argue that attentional demands differ across conditions. We cannot definitively rule out that mouth-breathing may have had differential effects on other unspecified attentional functions driven by, for example, stress and anxiety during the consolidation phase, but the overall picture presented by the converging evidence above suggests this is unlikely. Therefore, we conclude that differences in recognition memory are most likely attributable to differences in consolidation between nasal and mouth respiration per se, and not to differences in attention or discomfort that could arise as a side-effect of the main manipulation.

Animal and human studies have jointly demonstrated that memories are rapidly encoded in the hippocampus (Alvarez and Squire, 1994; Ison et al., 2015), that recognition memory related hippocampal activity is initiated immediately after learning (Stark and Squire, 2000), and that this activity persists over a $1 \mathrm{~h}$ interval (Peigneux et al., 2006). Replaying memories is a fundamental mechanism by which the initially encoded memory signal is amplified. During awake states, this replay is necessary for hippocampal-dependent consolidation and retrieval (Karlsson and Frank, 2009; O’Neill et al., 2010; Carr et al., 2011). This type of automatic reengagement of neural patterns during awake consolidation are present across the whole brain, but are especially evident for the hippocampus and associated with time intervals important for awake consolidation (Robertson, 2009). Disturbing the neural processes underlying awake consolidation has a direct negative impact on memory performance (Robertson, 2009). For example, both transcranial magnetic stimulation over neural circuits activated during consolidation, as well as behavioral tasks that compete over the same neural resources decrease later retrieval processes (Brown and Robertson, 2007; Robertson, 2009).

In the present study we demonstrated that the consolidation process can be modulated by the simple act of breathing alone. The fact that the respiratory shift was induced immediately after the encoding session indicates that these engage the first stages of the awake consolidation process. Whether similar respiratory locked effects arise for later stages, or during sleep-dependent consolidation, remains to be seen. Our results support the growing evidence that nasal respiration modulates perception and cognition in humans (Sobel et al., 1998; Bensafi et al., 2003, 2005; Mainland and Sobel, 2006; Simonyan et al., 2007; Arshamian et al., 2008; Perl et al., 2016; Zelano et al., 2016; Heck et al., 2017; Herrero et al., 2018).

Previous studies with humans have demonstrated nasal, but not mouth, cycle-by-cycle time-locking of hippocampus oscillations (Zelano et al., 2016). These oscillations are specifically modulated by the inhalation phase of the nasal cycle, and behavioral measures have demonstrated enhanced performance when solving complex cognitive tasks (e.g., visual recognition memory) during nasal inhalation but not exhalation; a pattern not seen for cycle-by-cycle mouth respiration (Zelano et al., 2016). In the present study there was no difference in the sniffing cycle across sessions during odor encoding and recognition. So the observed differences in recognition memory could not result from differential sniffing during these events. However, although each consolidation session removed the complete nasal or mouth respiratory cycle (i.e., inhalation/exhalation), we believe that the observed differences in recognition memory are primarily driven by the difference between nasal and mouth inhalation phases during consolidation. Although this study did not measure brain oscillations, we propose that one possibility for the reduction in $d^{\prime}$ could be the decreased communication between sensory (i.e., olfactory bulb) and memory networks (i.e., hippocampus) during consolidation when air is redirected to the mouth. One potential mechanism for this is that nasal inhalation increases the probability of SWRs activity in hippocampus during awake consolidation enabling a more effective replay of episodic events (Liu et al., 2017). However, changes in hippocampal activity may not be the only reason for changes in olfactory memory, because mouth-breathing could have affected other aspects of the consolidation phase, including olfactory imagery ability (Bensafi et al., 2003; Arshamian et al., 2008) and oxygen load in the brain (Sano et al., 2013).

The present study manipulated the respiratory cycle during consolidation to enable causal inference and to maximize potential effects on recognition memory between nasal and mouth respiration. However, it should be noted that the majority of individuals are habitual nose breathers (Warren et al., 1988). Future studies should also look how the natural respiratory cycle during consolidation is correlated with memory performance.

To conclude, we demonstrate for the first time that respiration mode during awake consolidation has behaviorally relevant consequences for episodic odor recognition, and underscore the critical role of the fundamental physiological process of breathing on the shaping of episodic memories.

\section{References}

Adrian ED (1942) Olfactory reactions in the brain of the hedgehog. J Physiol 100:459-473. CrossRef Medline

Alvarez P, Squire LR (1994) Memory consolidation and the medial temporal lobe: a simple network model. Proc Natl Acad Sci U S A 91:7041-7045. CrossRef Medline

Arshamian A, Olofsson JK, Jönsson FU, Larsson M (2008) Sniff your way to clarity: the case of olfactory imagery. Chemosens Percept 1:242-246. CrossRef

Axmacher N, Elger CE, Fell J (2008) Ripples in the medial temporal lobe are relevant for human memory consolidation. Brain 131:1806-1817. CrossRef Medline

Benjamin AS, Diaz M, Wee S (2009) Signal detection with criterion noise: applications to recognition memory. Psychol Rev 116:84-115. CrossRef Medline

Bensafi M, Porter J, Pouliot S, Mainland J, Johnson B, Zelano C, Young N, Bremner E, Aframian D, Khan R, Sobel N (2003) Olfactomotor activity during imagery mimics that during perception. Nat Neurosci 6:11421144. CrossRef Medline

Bensafi M, Pouliot S, Sobel N (2005) Odorant-specific patterns of sniffing during imagery distinguish "bad" and "good" olfactory imagers. Chem Senses 30:521-529. CrossRef Medline

Biskamp J, Bartos M, Sauer JF (2017) Organization of prefrontal network activity by respiration-related oscillations. Sci Rep 7:45508. CrossRef Medline

Brown RM, Robertson EM (2007) Off-line processing: reciprocal interactions between declarative and procedural memories. J Neurosci 27: 10468-10475. CrossRef Medline 
Buzsaki G (2006) Rhythms of the brain. Oxford; New York: Oxford UP.

Buzsáki G (2015) Hippocampal sharp wave-ripple: a cognitive biomarker for episodic memory and planning. Hippocampus 25:1073-1188. CrossRef Medline

Carr MF, Jadhav SP, Frank LM (2011a) Hippocampal replay in the awake state: a potential substrate for memory consolidation and retrieval. Nat Neurosci 14:147-153. CrossRef Medline

Cornell Kärnekull S, Jönsson FU, Willander J, Sikström S, Larsson M (2015) Long-term memory for odors: influences of familiarity and identification across 64 days. Chem Senses 40:259-267. CrossRef Medline

Courtiol E, Hegoburu C, Litaudon P, Garcia S, Fourcaud-Trocmé N, Buonviso N (2011) Individual and synergistic effects of sniffing frequency and flow rate on olfactory bulb activity. J Neurophysiol 106:2813-2824. CrossRef Medline

Fontanini A, Bower JM (2005) Variable coupling between olfactory system activity and respiration in ketamine/xylazine anesthetized rats. J Neurophysiol 93:3573-3581. CrossRef Medline

Fontanini A, Bower JM (2006) Slow-waves in the olfactory system: an olfactory perspective on cortical rhythms. Trends Neurosci 29:429-437. CrossRef Medline

Fontanini A, Spano P, Bower JM (2003) Ketamine-xylazine-induced slow $(<1.5 \mathrm{~Hz})$ oscillations in the rat piriform (olfactory) cortex are functionally correlated with respiration. J Neurosci 23:7993-8001. CrossRef Medline

Freeman WJ (1976) Quantitative patterns of integrated neural activity. In: Simpler networks and behavior, Chap 20 (Fentress JC, ed) Sunderland, MA: Sinauer.

Girardeau G, Benchenane K, Wiener SI, Buzsáki G, Zugaro MB (2009) Selective suppression of hippocampal ripples impairs spatial memory. Nat Neurosci 12:1222-1223. CrossRef Medline

Grosmaitre X, Santarelli LC, Tan J, Luo M, Ma M (2007) Dual functions of mammalian olfactory sensory neurons as odor detectors and mechanical sensors. Nat Neurosci 10:348-354. CrossRef Medline

Heck DH, McAfee SS, Liu Y, Babajani-Feremi A, Rezaie R, Freeman WJ, Wheless JW, Papanicolaou AC, Ruszinkó M, Sokolov Y, Kozma R (2017) Breathing as a fundamental rhythm of brain function. Front Neural Circuits 10:115. CrossRef Medline

Herrero JL, Khuvis S, Yeagle E, Cerf M, Mehta AD (2018) Breathing above the brain stem: volitional control and attentional modulation in humans. J Neurophysiol 119:145-159. CrossRef Medline

Hummel T, Sekinger B, Wolf SR, Pauli E, Kobal G (1997) "Sniffin' sticks": olfactory performance assessed by the combined testing of odor identification, odor discrimination and olfactory threshold. Chem Senses 22:3952. CrossRef Medline

Ison MJ, Quian Quiroga R, Fried I (2015) Rapid encoding of new memories by individual neurons in the human brain. Neuron 87:220-230. CrossRef Medline

Ito J, Roy S, Liu Y, Cao Y, Fletcher M, Lu L, Boughter JD, Grün S, Heck DH (2014) Whisker barrel cortex delta oscillations and gamma power in the awake mouse are linked to respiration. Nat Commun 5: 3572. CrossRef Medline

Jadhav SP, Kemere C, German PW, Frank LM (2012) Awake hippocampal sharp-wave ripples support spatial memory. Science 336:1454-1458. CrossRef Medline

Jarosz AF, Wiley J (2014) What are the odds? A practical guide to computing and reporting Bayes factors. J Probl Solving 7:2. CrossRef

Jeffreys H (1961) Theory of probability, Ed 3. Oxford: Oxford UP.

Karlsson MP, Frank LM (2009) Awake replay of remote experiences in the hippocampus. Nat Neurosci 12:913-918. CrossRef Medline

Kay LM (2014) Circuit oscillations in odor perception and memory. Prog Brain Res 208:223-251. CrossRef Medline

Kay LM (2015) Olfactory system oscillations across phyla. Curr Opin Neurobiol 31:141-147. CrossRef Medline

Kay LM, Freeman WJ (1998) Bidirectional processing in the olfactorylimbic axis during olfactory behavior. Behav Neurosci 112:541-553. CrossRef Medline

Kay LM, Beshel J, Brea J, Martin C, Rojas-Líbano D, Kopell N (2009) Olfactory oscillations: the what, how and what for. Trends Neurosci 32:207214. CrossRef Medline

Lamers MJ, Roelofs A, Rabeling-Keus IM (2010) Selective attention and response set in the Stroop task. Mem Cognit 38:893-904. CrossRef Medline
Larsson M (1997) Semantic factors in episodic recognition of common odors in early and late adulthood: a review. Chem Senses 22:623-633. CrossRef Medline

Liu Y, McAfee SS, Heck DH (2017) Hippocampal sharp-wave ripples in awake mice are entrained by respiration. Sci Rep 7:8950. CrossRef Medline

Love J, Selker R, Marsman M, Jamil T, Dropmann D, Verhagen AJ, Ly A, Gronau QF, Smira M, Epskamp S, Matzke D, Wild A, Rouder JN, Morey RD, Wagenmakers EJ (2018) JASP: graphical statistical software for common statistical designs. J Stat Softw, in press.

Macmillan NA, Creelman CD (2005) Detection theory: a user's guide. New York: Psychology.

Mainland J, Sobel N (2006) The sniff is part of the olfactory percept. Chem Senses 31:181-196. CrossRef Medline

Majid A, Speed L, Croijmans I, Arshamian A (2017) What makes a better smeller? Perception 46:406-430. CrossRef Medline

Morey RD, Rouder JN, Pratte MS, Speckman PL (2011) Using MCMC chain outputs to efficiently estimate Bayes factors. J Math Psychol 55: 368-378. CrossRef

Nguyen Chi V, Müller C, Wolfenstetter T, Yanovsky Y, Draguhn A, Tort AB, Brankačk J (2016) Hippocampal respiration-driven rhythm distinct from theta oscillations in awake mice. J Neurosci 36:162-177. CrossRef Medline

O’Neill J, Pleydell-Bouverie B, Dupret D, Csicsvari J (2010) Play it again: reactivation of waking experience and memory. Trends Neurosci 33:220 229. CrossRef Medline

Peigneux P, Orban P, Balteau E, Degueldre C, Luxen A, Laureys S, Maquet P (2006) Offline persistence of memory-related cerebral activity during active wakefulness. PLOS Biol 4:e100. CrossRef Medline

Perl O, Weiss T, Pinchover L, Secundo L, Mor N, Kahana R, Sela L, Sobel N (2016) The sniffing brain. In: Chemical senses, p 402. Oxford, UK: Oxford UP.

Prem V, Sahoo RC, Adhikari P (2013) Comparison of the effects of buteyko and pranayama breathing techniques on quality of life in patients with asthma: a randomized controlled trial. Clin Rehabil 27:133-141. CrossRef Medline

Robertson EM (2009) From creation to consolidation: a novel framework for memory processing. PLoS Biol 7:e19. CrossRef Medline

Robertson IH, Manly T, Andrade J, Baddeley BT, Yiend J (1997) "Oops!": performance correlates of everyday attentional failures in traumatic brain injured and normal subjects. Neuropsychologia 35:747-758. CrossRef Medline

Rojas-Líbano D, Frederick DE, Egaña JI, Kay LM (2014) The olfactory bulb theta rhythm follows all frequencies of diaphragmatic respiration in the freely behaving rat. Front Behav Neurosci 8:214. CrossRef Medline

Rouder JN, Speckman PL, Sun D, Morey RD, Iverson G (2009) Bayesian $t$ tests for accepting and rejecting the null hypothesis. Psychon Bull Rev 16:225-237. CrossRef Medline

Rouder JN, Morey RD, Speckman PL, Province JM (2012) Default bayes factors for ANOVA designs. J Math Psychol 56:356-374. CrossRef

Rouder JN, Morey RD, Verhagen J, Swagman AR, Wagenmakers EJ (2017) Bayesian analysis of factorial designs. Psychol Methods 22:304-321. CrossRef Medline

Saive AL, ROYET JP, Plailly J (2014) A review on the neural bases of episodic odor memory: from laboratory-based to autobiographical approaches. Front Behav Neurosci 8:240. CrossRef Medline

Sano M, Sano S, Oka N, Yoshino K, Kato T (2013) Increased oxygen load in the prefrontal cortex from mouth breathing: a vector-based near-infrared spectroscopy study. Neuroreport 24:935-940. CrossRef Medline

Simonyan K, Saad ZS, Loucks TM, Poletto CJ, Ludlow CL (2007) Functional neuroanatomy of human voluntary cough and sniff production. Neuroimage 37:401-409. CrossRef Medline

Sobel N, Prabhakaran V, Desmond JE, Glover GH, Goode RL, Sullivan EV, Gabrieli JD (1998) Sniffing and smelling: separate subsystems in the human olfactory cortex. Nature 392:282-286. CrossRef Medline

Stark CE, Squire LR (2000) Functional magnetic resonance imaging (fMRI) activity in the hippocampal region during recognition memory. J Neurosci 20:7776-7781. CrossRef Medline

Stroop JR (1935) Studies of interference in serial verbal reactions. J Exp Psychol 18:643-662. CrossRef

Tort ABL, Brankačk J, Draguhn A (2018) Respiration-entrained brain 
rhythms are global but often overlooked. Trends Neurosci 41:186-197. CrossRef Medline

Turkalj M, Živković J, Lipej M, Bulat Lokas S, Erceg D, Anzić SA, Magdić R, Plavec D (2016) The effect of mouth breathing on exercise induced fall in lung function in children with allergic asthma and rhinitis. Int J Pediatr Otorhinolaryngol 86:53-56. CrossRef Medline

Verrall AB, Julian JA, Muir DC, Haines AT (1989) Use of noseclips in pulmonary function tests. J Occup Med 31:29-31. Medline

Wagenmakers EJ, Marsman M, Jamil T, Ly A, Verhagen J, Love J, Selker R, Gronau QF, Šmíra M, Epskamp S, Matzke D, Rouder JN, Morey RD (2018) Bayesian inference for psychology. part I: theoretical advantages and practical ramifications. Psychon Bull Rev 25:35-57. CrossRef Medline

Warren DW, Hairfield WM, Seaton D, Morr KE, Smith LR (1988) The re- lationship between nasal airway size and nasal-oral breathing. Am J Orthod Dentofacial Orthop 93:289-293. CrossRef Medline

Yanovsky Y, Ciatipis M, Draguhn A, Tort AB, Brankačk J (2014) Slow oscillations in the mouse hippocampus entrained by nasal respiration. J Neurosci 34:5949-5964. CrossRef Medline

Zelano C, Montag J, Khan R, Sobel N (2009) A specialized odor memory buffer in primary olfactory cortex. PloS One 4:e4965. CrossRef Medline

Zelano C, Jiang H, Zhou G, Arora N, Schuele S, Rosenow J, Gottfried JA (2016) Nasal respiration entrains human limbic oscillations and modulates cognitive function. J Neurosci 36:12448-12467. CrossRef Medline

Zhong W, Ciatipis M, Wolfenstetter T, Jessberger J, Müller C, Ponsel S, Yanovsky Y, Brankačk J, Tort ABL, Draguhn A (2017) Selective entrainment of gamma subbands by different slow network oscillations. Proc Natl Acad Sci U S A 114:4519-4524. CrossRef Medline 